\title{
PENGEMBANGAN MEDIA BELAJAR KEGAWATDARURATAN MATERNAL ATONIA UTERI BERBASIS E-LEARNING (MOBILE APLICATION)
}

\author{
Rahajeng Siti Nur Rahmawati \\ Prodi Kebidanan Kediri Poltekkes Kemenkes Malang \\ Jl. KH.Wakhid Hasyim 64 B Kediri \\ Email : rahajengsnr81@gmail.com
}

\begin{abstract}
The research objective of this development is to get an overview of media development study maternal emergencies atonic-based e-learning (mobile aplication). The development model used in this study using the 4D model Thiagarajan modified. Three early stage in the procedure through which the $4 \mathrm{D}$ development in this study is a Define (definition), Design (planning) Develop (development). Media Mobile Learning is assessed by 1 application specialists, 1 specialist emergency, and 40 D-IV Midwifery students to determine the response of students. The instrument used in the form of a questionnaire. Applications developed contains six main menu, namely the theory, clinical and diagnosis, action, checklist, video, exercises and about the application.
\end{abstract}

\section{Keywords: mobile apps, media, emergency maternal atonic}

\section{PENDAHULUAN}

Upaya dalam meningkatkan mutu pendidikan, mutu guru/dosen merupakan salah satu komponen yang mempunyai peran sangat penting (Basuki Wibawa, 2003). Salah satu upaya untuk meningkatkan mutu pendidikan di sekolah adalah dengan cara perbaikan proses belajar mengajar atau pembelajaran. Berbagai konsep dan wawasan baru tentang pembelajaran di sekolah telah muncul dan berkembang seiring pesatnya ilmu pengetahuan dan teknologi. Guru/dosen sebagai pendidik yang menduduki posisi strategis dalam pengembangan sumber daya manusia, dituntut untuk terus mengikuti perkembangan konsep-konsep baru dalam dunia pendidikan (B. Suryosubroto, 2002).

Perkembangan metode pembelajaran banyak mengalami kemajuan, baik metode pembelajaran secara personal, media pembelajaran ataupun proses pembelajaran. Salah satu bentuk perkembangan teknologi informasi yang diterapkan di dunia pendidikan adalah media pembelajaran berbasis E-Learning. E-Learning merupakan sebuah inovasi yang sangat besar terhadap perubahan proses pembelajaran, dimana proses belajar tidak lagi hanya mendengarkan uraian materi dari guru tetapi siswa juga aktif seperti mengamati, melakukan, mendemonstrasikan dan sebagainya. Materi bahan ajar dapat divisualisasikan dalam berbagai format dan bentuk yang lebih dinamis dan interaktif sehingga mahasiswa akan termotivasi untuk terlibat lebih jauh dalam proses pembelajaran tersebut (Bisri, 2009 ; Sobri, 2014).

Visi Program Studi Diploma IV Kebidanan Kediri adalah menghasilkan Sarjana Sains Terapan Kebidanan yang unggul dalam kegawatdaruratan, kompeten dan kompetitif di tingkat nasional pada tahun 2018. Fenomena di pendidikan kesehatan selama ini menunjukkan bahwa dalam proses pembelajaran masih banyak tantangan di dalamnya. Rata-rata kelas nilai akhir Mata Kuliah Kegawatdaruratan Maternal 
Perinatal pada mahasiswa semester IV Program Studi Diploma IV Kebidanan tahun ajaran 2014/2015 adalah 69. Dari hasil pengamatan pada saat proses pembelajaran teori di kelas maupun pada saat pembelajaran praktek / ketrampilan di laboratorium dalam proses pembelajaran Mata Kuliah Kegawatdaruratan Maternal Perinatal pada mahasiswa semester IV Program Studi Diploma IV Kebidanan tahun ajaran 2014/2015 terdapat beberapa kelemahan yang mempengaruhi hasil belajar mahasiswa dan berdasarkan hasil diagnosa, maka ditemukan beberapa kelemahan diantaranya: 1) partisipasi mahasiswa rendah dalam kegiatan pembelajaran; 2) dominasi mahasiswa tertentu dalam proses pembelajaran; 3) mahasiswa kurang tertarik dengan cara menyampaikan materi (metode tidak bervariasi); 4) sebagian besar mahasiswa kurang termotivasi untuk belajar.

Berdasarkan latar belakang tersebut, maka peneliti tertarik melakukan penelitian tentang Pengembangan Media Belajar Kegawatdaruratan Maternal Atonia Uteri Berbasis E-Learning (Mobile Aplication).

\section{METODE PENELITIAN :}

Rancangan penelitian ini adalah action research. Sedangkan model pengembangan yang digunakan dalam penelitian ini menggunakan model 4D Thiagarajan termodifikasi. Tiga tahap awal pada prosedur pengembangan 4D yang dilalui pada penelitian ini adalah Define (pendefinisian), Design (perencanaan), Develop (pengembangan). Populasi adalah seluruh mahasiswa semester IV Prodi DIV Kebidanan Kediri. Sampel adalah mahasiswa Prodi DIV Kebidanan Kediri semester IV sebanyak 40 orang. Pengambilan sampel secara simple random sampling, yang diundi dengan lotre, sehingga setiap individu mempunyai kesempatan yang sama untuk diambil sebagai sampel. Pada kelompok I sejumlah 5 orang, kelompok II sejumlah 10 orang dan kelompok III sejumlah 25 orang. Instrumen yang digunakan dalam penelitian adalah lembar konsultasi media belajar (aplikasi mobile) kegawatdaruratan oleh pakar dan lembar kuesioner penggunaan media belajar (aplikasi mobile) kegawatdaruratan oleh mahasiswa. Proses pengolahan data menggunakan statistik deskriptif atau statistik inferensial. Definisi operasional media belajar kegawatdaruratan maternal atonia uteri berbasis E Learning (mobile application) adalah sebuah media belajar dengan menggunakan aplikasi mobile android dengan memori 14,89 MB.

\section{HASIL PENELITIAN}

Diskripsi Review Pakar Aplikasi : Proses penelitian pengembangan media belajar kegawatdaruratan maternal atonia uteri berbasis e-learning (mobile aplication) dalam pengerjaannya didampingi oleh pakar aplikasi. Berikut review dari pakar aplikasi :

a. Secara umum aplikasi sudah bagus, supaya aplikasi lebih menarik ditambahkan image GIF untuk animasi aplikasi agar ringan.

b. Untuk video sebaiknya di embed dari youtube, hanya saja ketika membuka video di aplikasi harus online.

c. Agar tampilan penuh, gunakan propertis fill heigh dan fill weight pada layar.

Diskripsi Review Pakar Kegawatdaruratan : Proses penelitian pengembangan media belajar kegawatdaruratan maternal atonia uteri berbasis e-learning (mobile aplication) dalam pengerjaannya didampingi oleh pakar kegawatdaruratan. Berikut review dari pakar kegawatdaruratan:

a. Materi yang disajikan pada aplikasi sudah diringkas dengan baik. Materi tentang kegawatdaruratan atonia uteri dan penangannya sudah disesuaikan dengan teori dan protap terkini.

b. Pada menu teori : pernyataan "placenta belum terlepas dan memijitmijit serta mendorong uterus" bukan 
penyebab atonia uteri tapi lebih ke inversio uteri.

c. Pada menu manifestasi klinis, pernyataan "Darah tidak merembes" dihilangkan.

d. Pada menu tindakan (pencegahan) : pernyataan "Manajemen Kala III sebagai langkah utama pencegahan atonia uteri" diletakkan diawal paragraf. Di item (penatalaksanaan) ditambahkan pernyataan "Harus diwaspadai untuk pemberian oksitosin masiv harus diobservasi karena sifatnya dapat menyebabkan hipotensi pada ibu". Pada tindakan KBI : "Sebelum tindakan KBI dilaksanakan, minta asisten untuk memasang IV line I untuk infus RL grojok dan II infus + drip oksitosin". Berikutnya pernyataan "keluarga diminta menyiapkan rujukan" direvisi menjadi "petugas segera menyiapkan rujukan", serta "pra rujukan dilaksanakan pemasangan kondom kateter".

e. Pada menu cheklist tindakan kondom kateter diberikan "antibiotik tripel" direvisi menjadi "antibiotik profilaksis dengan spektrum luas dengan mempertimbangkan riwayat alergi pasien".

f. Aplikasi seperti ini diharapkan bisa dikembangkan untuk materi kegawatdaruratan maternal yang lain.

Diskripsi Hasil Uji Pengembangan Media Belajar Kegawatdaruratan Maternal Atonia Uteri Berbasis ELearning (Mobile Aplication)

\section{A. Kelompok I}

Tabel 1. Hasil Uji Pengembangan Media Belajar Kegawatdaruratan Maternal Atonia Uteri

Berbasis E-Learning (Mobile Aplication) pada kelompok I

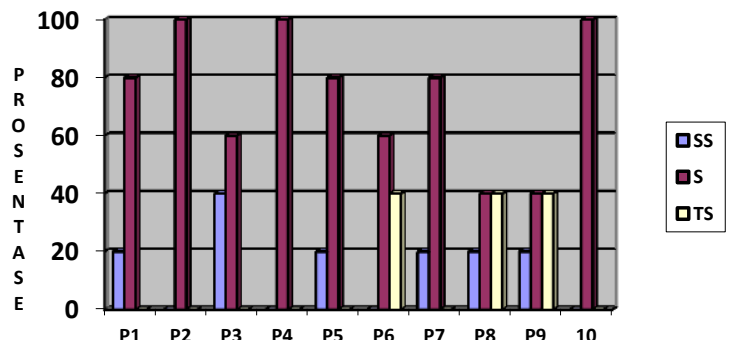

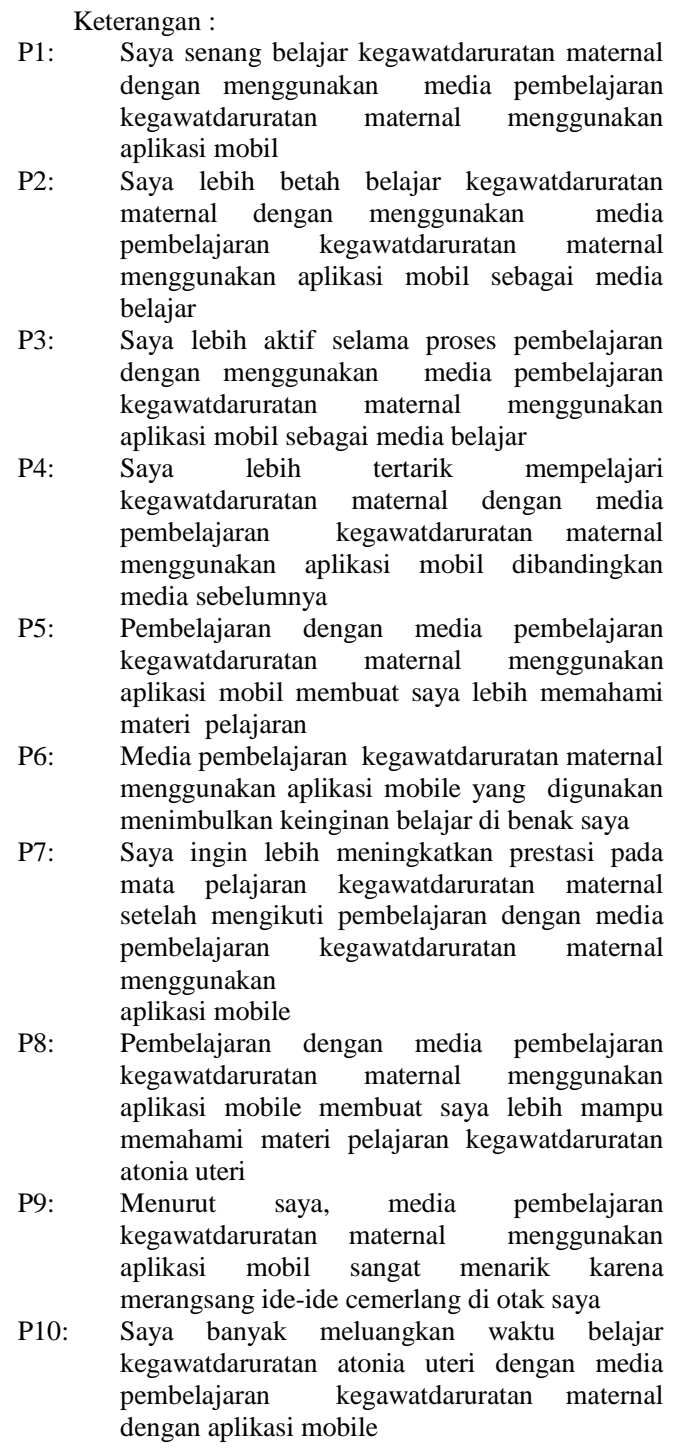

B. Kelompok II

Tabel 2. Hasil Uji Pengembangan Media Belajar Kegawatdaruratan Maternal Atonia Uteri

Berbasis E-Learning (Mobile Aplication) pada kelompok II 


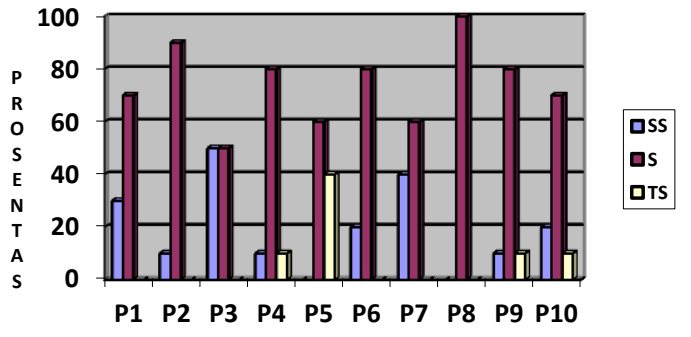

Keterangan :
P1: Saya
senang
belajar
kegawatdaruratan maternal dengan menggunakan media pembelajaran kegawatdaruratan maternal menggunakan aplikasi mobil

P2: Saya lebih betah belajar kegawatdaruratan maternal dengan menggunakan media pembelajaran kegawatdaruratan maternal menggunakan aplikasi mobil sebagai media belajar

P3: Saya lebih aktif selama proses pembelajaran dengan

menggunakan media pembelajaran kegawatdaruratan maternal menggunakan aplikasi mobil sebagai media belajar

P4: Saya lebih tertarik mempelajari kegawatdaruratan maternal dengan media pembelajaran kegawatdaruratan maternal menggunakan aplikasi mobil dibandingkan media sebelumnya

P5: Pembelajaran dengan media pembelajaran kegawatdaruratan maternal menggunakan aplikasi mobil membuat saya lebih memahami materi pelajaran

P6: Media pembelajaran kegawatdaruratan maternal menggunakan aplikasi mobile yang digunakan menimbulkan keinginan belajar di benak saya

P7: Saya ingin lebih meningkatkan prestasi pada mata pelajaran kegawatdaruratan maternal setelah mengikuti pembelajaran dengan media pembelajaran kegawatdaruratan maternal menggunakan aplikasi mobile

P8: Pembelajaran dengan media pembelajaran kegawatdaruratan maternal menggunakan aplikasi mobile membuat saya lebih mampu memahami materi pelajaran kegawatdaruratan atonia uteri

P9: Menurut saya, media pembelajaran kegawatdaruratan maternal menggunakan aplikasi mobil sangat menarik karena merangsang ide-ide cemerlang di otak saya

P10: Saya banyak meluangkan waktu belajar kegawatdaruratan atonia uteri dengan media pembelajaran kegawatdaruratan maternal dengan aplikasi mobile

\section{Kelompok III}

Tabel 3. Hasil Uji Pengembangan Media Belajar Kegawatdaruratan Maternal Atonia Uteri

Berbasis E-Learning (Mobile Aplication) pada kelompok III.

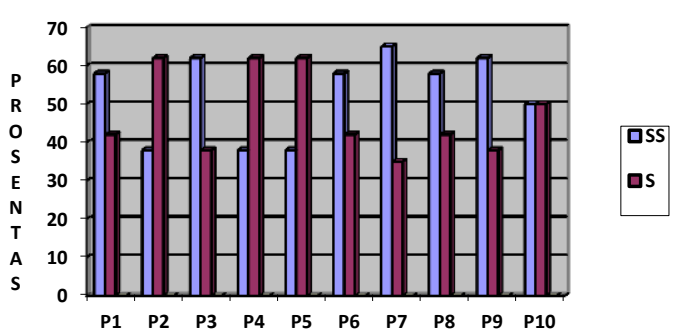

\section{Keterangan :}

P1: $\quad$ Saya senang belajar kegawatdaruratan maternal dengan menggunakan media pembelajaran kegawatdaruratan maternal menggunakan aplikasi mobil

P2: Saya lebih betah belajar kegawatdaruratan maternal dengan menggunakan media pembelajaran kegawatdaruratan maternal menggunakan aplikasi mobil sebagai media belajar

P3: Saya lebih aktif selama proses pembelajaran dengan

menggunakan media pembelajaran kegawatdaruratan maternal menggunakan aplikasi mobil sebagai media belajar

P4: Saya lebih tertarik mempelajari kegawatdaruratan maternal dengan media pembelajaran kegawatdaruratan maternal menggunakan aplikasi mobil dibandingkan media sebelumnya

P5: Pembelajaran dengan media pembelajaran kegawatdaruratan maternal menggunakan aplikasi mobil membuat saya lebih memahami materi pelajaran

P6: Media pembelajaran kegawatdaruratan maternal menggunakan aplikasi mobile yang digunakan menimbulkan keinginan belajar di benak saya

P7: Saya ingin lebih meningkatkan prestasi pada mata pelajaran 
kegawatdaruratan maternal setelah mengikuti pembelajaran dengan media pembelajaran kegawatdaruratan maternal menggunakan aplikasi mobile

P8: Pembelajaran dengan media pembelajaran kegawatdaruratan maternal menggunakan aplikasi mobile membuat saya lebih mampu memahami materi pelajaran kegawatdaruratan atonia uteri

P9: Menurut saya, media pembelajaran kegawatdaruratan maternal menggunakan aplikasi mobil sangat menarik karena merangsang ide-ide cemerlang di otak saya

P10: Saya banyak meluangkan waktu belajar kegawatdaruratan atonia uteri dengan media pembelajaran kegawatdaruratan maternal dengan aplikasi mobile

D. Komentar dan Saran dari Pengguna (Mahasiswa)

Tabel 4. Komentar dan Saran dari Pengguna (Mahasiswa)

\begin{tabular}{|c|c|}
\hline NO & KOMENTAR DAN SARAN \\
\hline 1 & $\begin{array}{l}\text { Mudah difungsikan, perpaduan warna } \\
\text { merah dan dasar hijau tidak sesuai }\end{array}$ \\
\hline 2 & $\begin{array}{l}\text { Menarik, bisa ditambahkan gambar } \\
\text { animasi }\end{array}$ \\
\hline 3 & $\begin{array}{l}\text { Simpel, enak dipakai belajar tidak harus } \\
\text { bawa buku }\end{array}$ \\
\hline 4 & Bagus, tapi video belum bisa dibuka \\
\hline 5 & $\begin{array}{l}\text { Ada latihan soalnya, tapi belum ada } \\
\text { kuncinya }\end{array}$ \\
\hline 6 & Bagus, jumlah latihan soalnya kurang \\
\hline 7 & Bermanfaat, Icon aplikasi kurang garang \\
\hline 8 & Menarik dan mudah dipelajari \\
\hline 9 & Bagus, tampilan di layar hp kurang lebar \\
\hline 10 & $\begin{array}{l}\text { Mudah dipakai, belum bisa pakai } \\
\text { tombol back }\end{array}$ \\
\hline 11 & $\begin{array}{l}\text { Asyiik dan keren, topik gadar atonia } \\
\text { uteri jadi lebih mudah dipelajari }\end{array}$ \\
\hline 12 & $\begin{array}{l}\text { Bagus, warna merah bagusnya dipadu } \\
\text { warna latar emas }\end{array}$ \\
\hline 13 & Bagus, jika ditambah efek suara \\
\hline 14 & Menarik, pakai gambar animasi \\
\hline 15 & $\begin{array}{l}\text { Bagus, dikembangkan untuk materi- } \\
\text { materi yang lain }\end{array}$ \\
\hline 16 & $\begin{array}{l}\text { Bagus, tapi masih pakai foto kampus IV } \\
\text { yang lama }\end{array}$ \\
\hline 17 & $\begin{array}{l}\text { Bagus, latihan soal bisa tahu skornya } \\
\text { berapa }\end{array}$ \\
\hline 18 & $\begin{array}{l}\text { Bagus, diusahakan bisa difungsikan } \\
\text { secara offline }\end{array}$ \\
\hline 19 & $\begin{array}{l}\text { Sudah bagus, video kondom kateter } \\
\text { agak bloor }\end{array}$ \\
\hline 20 & $\begin{array}{l}\text { Bermanfaat, bisa dikembangkan untuk } \\
\text { materi gadar/ matkul yang lain }\end{array}$ \\
\hline
\end{tabular}

\section{PEMBAHASAN}

Media pembelajaran yang dikembangkan berupa aplikasi mobile yang dapat dijalankan pada perangkat bergerak berbasis Android. Sehingga media pembelajaran yang dikembangkan dapat dijalankan kapan pun dan dimanapun. Media pembelajaran ini termasuk dalam kategori media pembelajaran berbasis E-learning (mobile learning). Hal ini sesuai dengan yang definisi mobile learning yang dinyatakan oleh O'Malley (2003), yaitu suatu pembelajaran yang pembelajar (learner) tidak diam pada satu tempat atau kegiatan pembelajaran yang terjadi ketika pembelajar memanfaatkan perangkat teknologi bergerak. Pada aplikasi ini terdapat tujuh menu utama, yaitu teori, klinis dan diagnosis, tindakan, cheklist, video,latihan soal dan tentang aplikasi. Beberapa bagian fitur dari aplikasi mobile akan menjadi keunggulan dari aplikasi (Huda, 2013). Pada menu "Teori" berisi definisi dan etiologi atonia uteri yang diharapkan akan dikuasai pengguna setelah mempelajari materi yang disajikan pada aplikasi. Pada menu "Klinis dan Diagnosis" berisi tanda dan gejala atonia uteri. Setelah mempelajari materi yang disajikan pada menu "Teori" dan "Klinis dan Diagnosis", pengguna dapat mempelajari menu "Tindakan Atonia Uteri" dimana pengguna dapat mempelajari pencegahan dan penatalaksanaan atonia uteri. Supaya pengguna dapat melaksanakan tindakan dengan tepat, maka pengguna dapat membuka menu"Chek List" dan melihat "Video". Untuk mengetahui pemahaman terhadap materi yang disajikan pada menu "Latihan Soal". Sementara menu "Tentang Aplikasi" berisi gambaran singkat tentang aplikasi. Adanya menumenu ini memungkinkan pengguna untuk memilih sendiri konten yang ingin dipelajari. Hal ini sesuai dengan pendapat Terrell(2011) tentang beberapa kriteria yang menjadikan mobile learning efektif. Pakar aplikasi memberikan review secara umum aplikasi sudah bagus, supaya aplikasi lebih menarik ditambahkan image GIF untuk animasi aplikasi agar ringan. Untuk video sebaiknya di embed dari 
youtube, hanya saja ketika membuka video di aplikasi harus online. Agar tampilan penuh, gunakan propertis fill heigh dan fill weight pada layar.

Review pakar kegawatdaruratan pada dasarnya materi secara keseluruhan sudah disesuaikan dengan teori terkini. Pakar kegawatdaruratan memberikan beberapa revisi pada menu teori : pernyataan "placenta belum terlepas dan memijitmijit serta mendorong uterus" bukan penyebab atonia uteri tapi lebih ke inversio uteri. Pada menu manifestasi klinis, pernyataan "Darah tidak merembes" dihilangkan. Sedangkan pada menu tindakan (pencegahan) : pernyataan "Manajemen Kala III sebagai langkah utama pencegahan atonia uteri" diletakkan diawal paragraf. Di item penatalaksanaan ditambahkan pernyataan "Harus diwaspadai untuk pemberian oksitosin masiv harus diobservasi karena sifatnya dapat menyebabkan hipotensi pada ibu". Pada tindakan KBI : "Sebelum tindakan KBI dilaksanakan, minta asisten untuk memasang IV line I untuk infus RL grojok dan II infus + drip oksitosin". Berikutnya pernyataan "keluarga diminta menyiapkan rujukan" direvisi menjadi "petugas segera menyiapkan rujukan", serta "pra rujukan dilaksanakan pemasangan kondom kateter". Berikutnya pada menu cheklist tindakan kondom kateter diberikan "antibiotik tripel" direvisi menjadi "antibiotik profilaksis dengan spektrum luas dengan mempertimbangkan riwayat alergi pasien". Aplikasi seperti ini diharapkan bisa dikembangkan untuk materi kegawatdaruratan maternal yang lain.

Berdasarkan hasil uji coba yang telah dilakukan pada 40 mahasiswa, diperoleh hasil yaitu media pembelajaran yang dikembangkan penulis layak untuk digunakan, dilihat dari tren hasil uji coba aplikasi pada tabel 1,2 dan 3 dimana mahasiswa secara umum menyatakan sangat setuju dan setuju dengan media pembelajaran kegawatdaruratan maternal atonia uteri. Berdasarkan tabel 4 . komentar para responden/ pengguna tentang media pembelajaran aplikasi kegawatdaruratan maternal atonia uteri adalah "menarik, bagus, keren, bermanfaat, mendukung proses belajar mereka pada materi kegawatdaruratan maternal atonia uteri, dan bisa dipelajari dimanapun tanpa harus membawa buku". Sedangkan saran dan masukan dari mahasiswa secara umum untuk perbaikan aplikasi dan pengguna berharap media pembelajaran berupa aplikasi seperti ini bisa dikembangkan untuk materi kegawatdaruratan maternal maupun mata kuliah yang lain. Dengan demikian media pembelajaran aplikasi mobile yang berbasis E-learning sesuai dengan teori yang menyebutkan bahwa E-learning juga ikut serta dalam meningkatkan mutu pendidikan di masa yang akan datang (Rusman, 2011).

Aplikasi yang dikembangkan pada penelitian ini tidak dapat dijalankan pada semua jenis perangkat mobile mengingat aplikasi ini hanya dapat dijalankan pada perangkat mobile berbasis Android. Dengan adanya pengembangan aplikasiaplikasi pembelajaran pada perangkat mobile diharapkan dapat meningkatkan manfaat perangkat mobile dalam bidang pendidikan dan memberikan motivasi belajar mahasiswa. Nugrahini (2011) menyebutkan "Dengan memanfaatkan taktik alat bantu yang mudah diterima (acceptable), guru dapat menggairahkan minat belajar siswa"(Nugrahani, 2007). Selain itu, adanya aplikasi-aplikasi seperti ini dapat memberikan pengalaman belajar yang menarik dan baru bagi mahasiswa.

\section{KESIMPULAN}

Produk yang dikembangkan yaitu media pembelajaran berupa aplikasi mobile berbasis Android. Aplikasi ini terdapat tujuh menu utama, yaitu teori, klinis dan diagnosis, tindakan, cheklist, video, latihan soal dan tentang aplikasi. Pakar aplikasi memberikan review secara umum aplikasi sudah bagus, supaya aplikasi lebih menarik ditambahkan image 
GIF untuk animasi aplikasi, video sebaiknya di embed dari youtube, serta agar tampilan penuh, gunakan propertis fill heigh dan fill weight pada layar. Sedangkan pakar kegawatdaruratan memberikan review materi yang disajikan pada aplikasi sudah sesuai teori, namun demikian ada beberapa pernyataan pada materi yang harus direvisi, serta aplikasi seperti ini diharapkan bisa dikembangkan untuk materi kegawatdaruratan maternal yang lain. Berdasarkan hasil uji coba yang telah dilakukan pada 40 mahasiswa, diperoleh hasil yaitu media pembelajaran yang dikembangkan penulis layak untuk digunakan, dilihat dari tren hasil uji coba aplikasi pada secara umum menyatakan sangat setuju dan setuju serta komentar saran positif terkait pengembangan media pembelajaran kegawatdaruratan maternal atonia uteri berupa aplikasi mobile.

\section{SARAN}

Pengembangan Media Belajar Kegawatdaruratan Maternal Atonia Uteri Berbasis E-Learning (Mobile Aplication) dapat dikembangkan dengan materi kegawatdaruratan maternal yang lain serta penelitian ini dapat dikembangkan lebih lanjut pada tahap development dan dessiminatte.

\section{DAFTAR PUSTAKA}

Abin Syamsudin. 1996. Psikologi Kependidikan. Bandung: PT Remaja Rosda Karya.

Basuki Wibawa. 2003. Penelitian Tindakan Kelas. Jakarta: Depdiknas.

Brian Clegg. 2001. Instant Motivation: 79

Cara Instan Menumbuhkan Motivasi. Jakarta: Erlangga.

Bustang. 2010. Pengembangan Perangkat

Pembelajaran Matematika

Berbahasa Inggris Berbasis

Realistik pada SMP Rintisan

Sekolah Bertaraf Internasional.

Skripsi. Universitas Negeri

Makassar.
B. Suryosubroto. 2002. Proses Belajar Mengajar di Sekolah. Jakarta: Rineka Cipta.

Cunningham, F.Gary, Norman F. Gant, et all.2009. Williams Obstetrics international edition. 21 st edition.

E. Mulyasa. 2003. Kurikulum Berbasis Kompetensi:

Konsep,

Karakteristik, dan Implementasi. Bandung: Remaja Rosdakarya.

Hamzah B. Uno. 2008. Teori Motivasi dan Pengukurannya Analisis di Bidang Pendidikan. Jakarta: Bumi Aksara.

JNPK-KR. 2008. Asuhan Persalinan

Normal. Jakarta : Depkes RI

Khasan Bisri. 2009. Efektivitas Penggunaan Metode

Pembelajaran E-learning Berbasis Browser Based Training Terhadap Prestasi Belajar Siswa Pada Kompetensi Pemeliharaan/ Servis Transmisi Manual dan Komponen.UNS

Maryunani, dkk. 2011. Asuhan Kegawatadaruratan Maternal dan Neonatal. Jakarta : TIM

Moh. Uzer Usman. 2003. Upaya Optimalisasi Kegiatan Belajar Mengajar. Bandung: Remaja Rosdakarya.

Muhammad, Sobri. 2014. Efektivitas Pembelajaran Media E-Learning Berbasis Web Dan Konvensional Terhadap Tingkat Keberhasilan Belajar Mahasiswa (Studi Kasus Mahasiswa Fakultas Ekonomi Universitas Bina Darma Palembang). SNASTIKOM.

Murray, Sharon Smith \& Emily Slone McKinney. 2007. Foundations of Maternal-Newborn Nursing 4th Edition. Singapore: Saunders.

Nana Sudjana. 2004. Dasar-Dasar Proses Belajar Mengajar. Bandung: Sinar Baru Algensindo

Nasution. 2005. Berbagai Pendekatan dalam Proses Belajar Mengajar. Jakarta: Bumi Aksara. 
Nugrahani, Rahina.2007. Media Pembelajaran Berbasis Visual Berbentuk Permainan Ular Tangga Untuk Meningkatkan Kualitas Belajar Mengajar Di Sekolah Dasar. Semarang. Jurnal Lembaga Ilmu PendidikanUniversitas Negeri Semarang.

Nursalam dan Ferry Efendi. 2008. Pendidikan dalam Keperawatan. Jakarta: Salemba Medika.

Oemar Hamalik. 1995. Metode Belajar dan Kesulitan-Kesulitan Belajar. Bandung: Remaja Rosdakarya.

O'Malley,C, dkk. 2003. Guidelines For Learning/ Teaching/ Tutoring in a Mobile Environtment (Online), (http://www.mobilearn.org/downlo ad/results/guidelines.pdf, diakses pada 15 Oktober 2016)

Poerwanto, Ngalim. 2007. Psikologi Pendidikan. Bandung: PT Rosda Karya.

Rusman. 2011. Pembelajaran Berbasis Teknologi Informasi dan Komunikasi Mengembangkan Profesionalitas Guru. Jakarta: Raja Grafindo Persada.

Saefudin, Abdul Bari, dkk. 2007. Pelayanan Kesehatan Maternal dan Neonatal. Jakarta : Yayasan Bina Pustaka Sarwono Prawirohardjo

Sugiyono. 2012. Metodologi PenelitianKuantitatif Kualitatif dan $R \& D$. Bandung : Alfabetha

Terrell, Shelly Sanchez. 2011. Effective Mobile Learning, 50 + Quick Tips $\&$ Resources, (Online), (http://www.scribd.com/doc/67369 598/Effective-Mobile-Learning50- Tips-Resources-Ebook, diakses pada 19 November 2016)

Thiagarajan, S., Semmel, D. S \& Semmel, M. I. 1974. Instructional Development for Training Teachers of Expectional Children. Minneapolis, Minnesota: Leadership Training Institute/Special Education, University of Minnesota.
Wiknjosastro, Hanifa. 2009. Ilmu Kebidanan. Jakarta : PT. Bina Pustaka Sarwono Prawirohardo.

http://mkhuda.com/teknologi/4perbedaan-aplikasi-mobiledengan-aplikasi-webdesktop/Posted on April 27, 2013 by Muhammad K Huda 